Revista Punto Género № 8. Diciembre de 2017

ISSN 0719-0417 / 39 - 54

\title{
Paridad de género en los debates políticos argentinos
}

Gender parity in Argentinian's political debates

\author{
Micaela Soledad Cano* y Julieta Evangelina Cano**
}

\section{Resumen}

Recientemente en la provincia de Buenos Aires se aprobó la ley de paridad de género en las listas electorales, no sin acalorados debates acerca de la necesidad de la ley, como así también de la justicia o injusticia que la sanción de la misma representa.

Con motivo de la sanción de dicha ley y el debate que generó a nivel nacional, nos proponemos sistematizar los argumentos a favor y en contra de los derechos políticos de las mujeres en Argentina. Para acercarnos a nuestro objetivo usaremos como fuente principal las versiones taquigráficas de los debates parlamentarios en ocasión ley de paridad bonaerense de 2016. Por su novedad en nuestro país, esta ley reactivó discursos contrarios a la participación femenina que ya creíamos superados. Este trabajo busca identificar los argumentos que evidencian resistencias a la participación política de las mujeres, y cómo estos argumentos son reediciones de antiguos argumentos, ya vertidos en el recinto parlamentario cada vez que este tema logró ingresar a la agenda política.

Consideramos también importante contextualizar el momento actual y, en pos de construir conocimiento situado, realizamos un breve recorrido histórico sobre la participación política de las mujeres en Argentina. Nuestra intención es identificar los discursos en juego, constructores de la ciudadanía femenina.

Palabras clave: Debates parlamentarios - paridad de género - derechos políticos de las mujeres.

\begin{abstract}
Recently, in the province of Buenos Aires, the law of gender parity on the electoral lists was approved without heated debate about the "necessity" of the law, as well as justice or injustice of the new representation law.
\end{abstract}

As a result of the enactment of this law and the debate at national level that generated, our intention is to systematize the arguments for and against the political rights of women in Argentina. To get closer to our objective we will use as main source the shorthand versions

\footnotetext{
* Abogada por la Universidad Nacional de La Plata.

** Abogada por la Universidad Nacional de La Plata. Becaria Doctoral UNLP con sede en el Instituto de Cultura Jurídica.
} 
of the parliamentary debates on occasion of the Buenos Aires parity law of 2016. For its novelty in our country, this law reactivated discourses contrary to the women's participation that we already believed surpassed. This work looks for identify the arguments that show resistance to women's political participation, and how these arguments are reissues of old arguments already spilled in the parliamentary area whenever this issue managed to enter the agenda politics.

We also consider that it is important to contextualize the present moment and, in order to construct situated knowledge, we make a brief historical tour of the political participation of women in Argentina. Our intention is to identify the discourses at play, constructors of feminine citizenship.

Key words: Parliamentary debates - gender parity - political rights of women

Fecha de recepción: 03 de marzo 2017

Fecha de aprobación: 18 de enero 2018

\section{Introducción}

Recientemente en la provincia de Buenos Aires se aprobó la ley de paridad de género en las listas electorales, no sin acalorados debates acerca de la necesidad de la ley, como así también de la justicia o injusticia que la sanción de la misma representa.

Con motivo de la sanción de dicha ley y el debate que generó a nivel nacional la posibilidad de una ley de paridad que abarque todo el territorio de la nación, nos proponemos sistematizar los argumentos a favor y en contra de los derechos políticos de las mujeres en Argentina. Para acercarnos a nuestro objetivo usaremos como fuente principal las versiones taquigráficas de los debates parlamentarios en ocasión ley de paridad bonaerense de 2016. Por su novedad en nuestro país, esta ley reactivó discursos contrarios a la participación femenina que ya creíamos superados. La principal contribución de este trabajo se relaciona con identificar cuáles son los argumentos que evidencian resistencias a la participación política de las mujeres, y cómo estos argumentos son reediciones de antiguos argumentos ya vertidos en el recinto parlamentario cada vez que este tema logró ingresar a la agenda política.

Consideramos también importante contextualizar el momento actual y, en pos de construir conocimiento situado, realizamos un breve recorrido histórico sobre la participación política de las mujeres en Argentina, deteniéndonos en la ley Saenz Peña de 1912, la ley de sufragio femenino de 1947 y la ley de cupo de 1991. Nuestra intención es identificar los discursos en juego en cada uno de esos momentos, constructores de la ciudadanía femenina. 
Revista Punto Género № 8. Diciembre de 2017

ISSN 0719-0417 / 39 - 54

\section{De la ley Saenz Peña al voto universal}

En el año 1912 se sanciona en Argentina la ley № 8.871 conocida como ley Saenz Peña o del sufragio universal, ampliando los derechos políticos a toda la población masculina y, en el mismo momento, naturalizando la no-ciudadanía política de las mujeres. Sin embargo, al momento de la pretendida ley de voto universal hubo varias voces que reclamaban por los derechos políticos de las mujeres, porque ésta era una postergación combatida desde varios países del mundo en todo occidente. Treinta y cinco años pasaron para que la universalidad se materialice, con la sanción de la ley 13.010 en el año 1947.

El activismo femenino fue crucial para la obtención de los derechos (Palermo, 2007) ${ }^{1}$ dado que las mujeres no aceptaban de manera sumisa esta exclusión "si bien los derechos políticos crecieron rezagados respecto de otros derechos (especialmente los civiles y sociales), los años 20 encontraron un período de esplendor para el sufragismo local: se realizaron dos simulacros electorales en los cuales las representantes más conspicuas fueron candidatas" (Valobra, 2008: párrafo 9).

El primer proyecto a favor del sufragio femenino en Argentina fue presentado en 1919 por Rogelio Araya (Valobra, 2008), pero hubo que esperar hasta 1947 para que la demanda se convirtiera en ley, y hasta 1951 para que las mujeres pudieran votar por primera vez. La sanción del sufragio femenino en Argentina se enmarca en una tercera ola de reconocimientos de los derechos políticos de las mujeres. Después de la Primera Guerra Mundial se reconoció el derecho al voto a las mujeres en Europa excepto Francia (Perrot, 2008), en un segundo momento se avanzó en tal reconocimiento entre los años 30 y 40 (Palermo, 2007) y, por último, la denominada tercera ola de reconocimiento se dio entre la Segunda Guerra Mundial y los años 60. Es importante aclarar que la Segunda Guerra Mundial provocó una disminución en la demanda y el activismo por el voto femenino, dado que muchas mujeres priorizaron la lucha integrada en contra de la amenaza de los totalitarismos sobre su demanda específica.

No podemos pensar que la ciudadanía política de las mujeres es una conquista consolidada, porque aunque las mujeres tienen derecho a votar y pueden ser elegidas, esa elección se basa sobre un supuesto de abstracción en donde varones y mujeres estarían en igualdad de condiciones para ser elegidos/as, y esto no se verifica en la realidad. ¿Cuáles eran las razones para excluir a las mujeres del campo de acción política? ¿Siguen esas razones siendo esgrimidas en la actualidad para limitar el campo de acción política femenino? Hoy

\footnotetext{
${ }^{1}$ La exclusión de las mujeres no era ni siquiera expresa: el colmo de la invisibilización. ¿Por qué, entonces, las mujeres no podían votar? Pues aunque la ley no prohibía el sufragio expresamente, al estar el padrón electoral basado en el padrón militar (Ansaldi, 1999), y al excluirse a las mujeres de la integración de las fuerzas armadas, la tácita prohibición se materializaba en silencio.
} 
Revista Punto Género № 8. Diciembre de 2017

ISSN 0719-0417 / 39 - 54

como ayer están presentes los estereotipos de género en las argumentaciones. La dualidad jerarquizada (Olsen, 2009) en la que está concebido y organizado el mundo, sitúan a la mujer en el lado de lo débil -en contraposición a lo fuerte-, del lado de lo emocional -en contraposición a lo racional- y de lado de lo inferior -en contraposición a lo superior-. Esta interiorización construida culturalmente y sostenida teóricamente fue una de las razones por las cuales a las mujeres no se las consideraba aptas ni siquiera para opinar de temas políticos, y aún hoy muchas mujeres son descalificadas en ese terreno, solo por el hecho de ser mujeres.

El debate parlamentario sobre el sufragio femenino efectivamente se dio en la década del '30, porque para cuando se sanciona efectivamente la ley 13.010 en 1947, el oficialismo tenía la mayoría y existían ciertos consensos al respecto. La estrategia de los sectores conservadores cuando apoyaron los derechos políticos femeninos fue clara: estaban convencidos de que el voto de la mujer se definiría por la derecha: sería el marido o la iglesia quienes le dijeran a la mujer a quien votar (Barrancos, 2007, Valobra, 2010).

Cuando en la década del '30 se debatió acerca de los derechos políticos de las mujeres, se manifestó un temor discursivo en el recinto parlamentario, relativo a la inevitable disolución de la familia cuando las mujeres pudieran votar "[el Diputado Francisco Uriburu] dijo que otorgar el sufragio femenino es "fomentar la disolución de la familia con gérmenes de anarquía, es disminuir el poder marital ya socavado por la acción económica de la mujer, es propender a la disminución de los matrimonios" (...) implicaba "la supresión del privilegio de su debilidad" (Barrancos, 2007:162). Podemos observar entonces, que se invocaba un genuino temor por la disolución de la familia como base de la sociedad, y por ende, se auguraba el caos, por atentar contra el poder marital. Nunca más evidente el goce expreso de los privilegios masculinos.

El fundamento último de la exclusión de las mujeres de la arena política, se basa en el contrato sexual (Pateman, 1995) que otorga la prerrogativa al colectivo de varones, no sólo de acceder a los cuerpos de las mujeres, sino de definir su presente y futuro como miembros de la sociedad. Con las demandas por ciudadanía, la rígida división de lo público y lo privado, el primero de estos mundos reservado para los varones y el segundo asignado con exclusividad a las mujeres, se veía amenazado por las reivindicaciones feministas que abogaban por una igualdad, legal y real.

La consecuencia más remarcable de la sanción de una ley que permitiera a las mujeres elegir y ser elegidas en condiciones de igualdad con los varones, fue la posibilidad de trascender del ámbito familiar y doméstico como una realidad concreta. Ya el acceso a la educación y el trabajo nos permitieron a las mujeres cuestionar la jerarquización de los sexos dentro del sistema patriarcal (Valobra, 2010). Si la naturalidad de la mujer indicaba que su lugar estaba en la casa, el derecho a elegir y ser elegida en la arena política cuestionaba -a veces sin querer- esta ideología de la domesticidad. Aun cuando la ley nro. 
13.010 se puede analizar desde una perspectiva estratégica para aumentar el caudal político (Palermo, 2007), lo cierto es que esta medida se tradujo en cambios considerables para la identidad femenina "(...) al cuestionar las jerarquías construidas sobre la base de las diferencias de género y al glorificar los atributos de la mujer de pueblo para la participación política" (Palermo, 2007:29). Incluso, pensándolo desde la voz que les otorgaba la ley, para discutir cuestiones políticas en la mesa del hogar.

Como se ha señalado sucintamente, el sufragio femenino se dio en un contexto internacional favorable que demandaba ese reconocimiento (Palermo, 2007; Barrancos, 2007), y nuestro país se hizo eco, no sólo de las demandas externas, sino también de las internas. Las mujeres se constituyen, entonces, como nuevos sujetos políticos y como una potencial "clientela política" apetecible (Valobra, 2008).

\section{Los ' 90 y los debates acerca del CUPO}

"Si arriban a los espacios políticos mujeres con conciencia, tradición y acciones políticas de género, su presencia y participación contribuye a llevar a la esfera de la política, las necesidades, las aspiraciones, los intereses, las denuncias y las propuestas de mujeres que construyen alternativas sociales"

Marcela Lagarde, 2012: 303

Sancionada en el año 1991, la Ley Nacional nro. 24.012 fue un hito en Latinoamérica. Destaca por representar una avanzada en términos de igualdad de género en ámbitos reservados mayoritariamente en la sociedad a los varones. Las mujeres teníamos el derecho a circular por la esfera pública, pero a partir de esta ley se garantiza cierta representación para debatir en la arena política.

El proyecto de ley, vigente actualmente a nivel nacional, y cuya autora fue la Senadora Margarita Malharro de Torres ${ }^{2}$, modificó el Código Electoral de Nación en su artículo 60 para prescribir de manera obligatoria que las listas de candidatos presentados por los partidos políticos deben estar integradas por mujeres en un mínimo de $30 \%$ y en "proporciones para resultar electas", teniendo como sanción la no oficialización aquellas que no cumplieran con tales recaudos.

${ }^{2}$ Senadora por la provincia de Mendoza e integrante del bloque de la Unión Cívica Radical, quien inicia su exposición con la respuesta de "ustedes me quieren ver muda" a comentarios de sus colegas que expresaban que "la querían". 
Revista Punto Género № 8. Diciembre de 2017

ISSN 0719-0417 / 39 - 54

El debate que se dio en aquella ocasión en la Honorable Cámara de Senadores estuvo dividido en dos posiciones: aquellas que apoyaban el dictamen de mayoría de las Comisiones de Asuntos Constitucionales y Legislación General, aconsejando que el proyecto volviera a comisiones para hacer un sondeo en partidos políticos con la finalidad de pedir su opinión acerca del mismo, y el dictamen de minoría que apadrinaba la aprobación.

Destacamos primeramente que en ese momento el Senado contaba con 46 escaños, y sólo 4 Senadoras. Además, las primeras voces que se escucharon al comenzar el debate del proyecto, por ser a partir de una lista hecha a pedido de palabra, fueron de varones Senadores, y no así de la mujer que lo impulsó. En el Congreso, el uso de la palabra fue primordialmente para explicar los motivos por los cuales se hacía necesaria tal medida en nuestra sociedad, para garantizar que las mujeres sean elegidas candidatas en el seno de los partidos y también puedan sortear el obstáculo cultural de acceder a los lugares de poder y toma de decisiones que representa en Congreso Nacional.

En el recinto parlamentario se puso de manifiesto, en ocasión de debatir el proyecto, que el impulso del proyecto perteneció al colectivo de las mujeres argentinas, y que su sanción, más allá de un porcentaje, "es la incorporación de un aporte, una participación inteligente" (Senador Losada) y que se estuviera debatiendo en el recinto era un logro, ya que atravesó muchas vicisitudes para llegar hasta ese momento. Una vez más, el movimiento feminista logró que lo personal se convirtiera en político, como tantas otras veces en que los derechos de las mujeres se ponen en cuestión.

Los argumentos que sustentaban el proyecto fueron irrebatibles: se trató de la representación real de todos los sectores que integran la sociedad, para alcanzar la "democracia definitiva" y que las mujeres, como ciudadanas, recuperarán "el protagonismo que la negación de las libertades le ha impedido en nuestra sociedad" (Senadora Margarita Malharro de Torres). Pero a pesar de su simpleza, estos razonamientos fueron fuertemente resistidos.

Haciendo un recorrido por el debate, las razones para apoyar el proyecto destacan que las mujeres en los partidos políticos muchas veces son llamadas a ocupar tareas de diligencia en las campañas electorales para así obtener votos favorables, quedando estancadas en la militancia de base sin acceso a lugares de toma de decisiones, o, en caso de ser elegidas, muchas veces eran obligadas a renunciar a su banca -para dejarle el lugar a un varón-. También se denuncia el acoso y la violencia psicológica sufrida por las mujeres por parte de sus pares, como la violencia simbólica ejercida por los medios de comunicación. Todas estas, como manifestaciones de la violencia política ${ }^{3}$ que es ejercida hacia ellas a modo de

${ }^{3}$ Tomamos la definición del Art 7 inc B) de la Ley 243 del Estado Plurinacional de Bolivia define a la violencia política como "las acciones, conductas y/o agresiones físicas, psicológicas, sexuales cometidas por una persona o grupo de personas, directamente o a través de terceros, en contra de las mujeres candidatas, electas, designadas o en ejercicio de la función político - pública, o en contra de su familia, para acortar, suspender, impedir o restringir el ejercicio de su cargo o para 
Revista Punto Género № 8. Diciembre de 2017

ISSN 0719-0417 / 39 - 54

"estrategias para mantener los espacios de poder", al encontrar tal competencia como una amenaza al statu quo, como afirma Laura Albaine (2014).

La violencia política contra las mujeres tiene distintas manifestaciones, y como sostienen Krook y Sanín, las formas utilizadas son:

[...] usar imágenes o estereotipos de género para atacar a las oponentes mujeres, hace que las acciones se conviertan en un caso de violencia contra las mujeres en política, puesto que sugiere que las mujeres no pertenecen a lo político. Estas acciones tienen un profundo impacto puesto que no están dirigidas contra una sola mujer sino que también tienen el propósito de intimidar a otras mujeres políticas, disuadir a otras mujeres que puedan considerar una carrera política y, peor aún, comunicar a la sociedad en general que las mujeres no deberían participar (Krook y Sanín, 2016:139).

Tanto los argumentos a favor como en contra de la ley estuvieron plagados de estereotipos de género relativos a las mujeres (según el rol que impone la sociedad patriarcal), caracterizada como aquella que "apuntala a sus hombres en momento de debilidad, ofreciendo sus hijos cuando la patria lo reclama" (Senador Sánchez) o que "Ias mujeres resignan voluntariamente cargos públicos en un acto de conciencia en el que han expresado que no estaban capacitadas para ocupar tal o cual cargo" (Senador Sánchez), dejando la responsabilidad de incorporarlas en el arbitrio y buena voluntad de los partidos políticos y que aquellas que han llegado sin necesidad de acciones positivas lo han hecho "casi disfrazadas de hombre ${ }^{4 \prime}$, en una clara subversión al rol tradicional mandadas a ocupar.

Es notable que, aun en la actualidad, 26 años después del debate por la ley de cupo, se encuentre vigente en el imaginario social muchos de los argumentos para restringir los derechos de las mujeres a participar en igualdad. El argumento más habitual y teñido de liberalismo por excelencia es el referido a la idoneidad y capacidad. La llamada meritocracia es la aptitud que tiene una persona a llegar a un puesto, por el hecho de ser merecedor o merecedora del mismo a partir de los logros y su carrera, traduciéndose en la idoneidad para ejercer el mismo gracias a su formación y recorrido político.

La meritocracia tiene raigambre liberal. Nuestra Constitución Nacional establece que "todo argentino puede ser candidato", pero esta igualdad formal rara vez se traduce en igualdad real, porque invisibiliza los obstáculos que enfrentan las mujeres para acceder a las esferas del poder. La supuesta meritocracia niega la real falta de acceso que tienen muchas las mujeres para hacer carrera política, las complicaciones relativas al tiempo, factores

inducirla u obligarla a que realice, en contra de su voluntad, una acción o incurra en una omisión, en el cumplimiento de sus funciones o en el ejercicio de sus derechos".

${ }^{4}$ Haciendo alusión a la Primer Ministra de Inglaterra Margaret Thatcher. 
Revista Punto Género № 8. Diciembre de 2017

ISSN 0719-0417 / 39 - 54

económicos y financieros necesarios para las campañas electorales, la división sexual del trabajo, la carga casi en exclusividad del trabajo doméstico: cuando sobre su espalda también recaen las obligaciones domésticas, el cuidado de los y las hijas, el cuidado de la salud y la educación del grupo familiar, dejándoles poco tiempo para destinar a la militancia y para jerarquizarse políticamente. Es la Diputada Nacional Botella, quien resume lo antedicho en una frase:

Desgraciadamente, cuando a las mujeres se nos pide capacidad y excelencia, en realidad se nos está exigiendo tres veces más de capacidad que a los hombres y quizás cinco veces más de excelencia. En lo personal debo confesar que muchas veces he votado por disciplina partidaria, ya que sin pretender ofender a ninguno de los legisladores presentes, no siempre los candidatos que voté se caracterizaron por su idoneidad.... (Diputada Botella)

Las mujeres en la sociedad argentina en ese momento histórico-político, igual que hoy en día, no eran ajenas a la militancia, y aunque activas en sus partidos políticos, no superaron el 3\% de la representación en las Cámaras Legislativas de la Nación, por lo cual la promulgación de esta ley de discriminación positiva, con obligatoriedad y sanción fue la base para el incremento de la presencia, y el cambio cultural necesario. Aun así, las mismas resistencias se observaron 25 años después en el debate en la legislatura bonaerense en ocasión de discutir la ley de paridad de género.

\section{Paridad de género: debates y resistencias}

Claramente tenemos que discutir las cuestiones vinculadas a idoneidad, a capacidad o a competencias, pero también tenemos que hacer autocrítica. ¿Todos los hombres que hemos llegado a cargos electivos, hemos sido competentes? ¿Hemos sido idóneos? ¿Hemos sido capaces?

Diputado Bonelli

Argentina es un país federal, y como tal las provincias tienen autonomía para regular aquellos ámbitos que expresamente no le delegaron al poder central en la Constitución Nacional. En relación con los derechos políticos de las mujeres, la legislación de las provincias puede clasificarse en aquellas que tienen vigente leyes de cupo -son mayoría y están en consonancia con la ley nacional nro. 24.012- y aquellas provincias que, en minoría pero en consonancia con los derechos humanos de las mujeres y con la necesidad de una igualdad real de oportunidades, legislaron leyes provinciales previendo la paridad de género en los cargos electivos. Cronológicamente, la primera provincia en tener ley de paridad de género en las listas electorales fue Córdoba (2000). Le siguieron Río Negro (2011), Buenos Aires (2016) y, finalmente, Salta (Noviembre 2016). 
Haciendo un análisis del articulado de las leyes antes mencionadas, encontramos ciertas características comunes: todas remiten a la obligatoriedad de la participación equivalente, es decir 50\% de cada género en forma alternada, en las listas que se presenten para cubrir cargos electivos, bajo pena de no oficialización para aquellas que no cumplen con tal recaudo. Es prerrogativa de los colegios electorales o, en su caso, la justicia electoral, compeler a su reforma y de no operarse tal reforma, puede, de oficio, re-ordenar los cargos.

En este apartado nos interesa centrarnos en el debate parlamentario que se dio en ocasión de la sanción de la ley en la provincia de Buenos Aires, dado que fue la que más debate social generó, por ser la provincia más poblada del país, y porque además en la actualidad tiene como titular de su poder ejecutivo a la primera mujer de su historia. En septiembre de 2016, se debatió la modificación de la ley electoral para incluir la participación política equitativa entre géneros para todos los cargos públicos electivos de la provincia. Este debate en el recinto también provocó un debate en la sociedad acerca de la conveniencia y la justicia de leyes de este tipo, que podríamos enmarcar dentro de las medidas de acción positiva que prevé la Convención para la eliminación de todas las formas de discriminación contra la mujer, que cuenta con rango constitucional.

En la Cámara de diputados/as que sancionó la ley de reforma electoral, al momento de debatir la paridad de género en las listas de candidatos/as, presentaron sus argumentos nueve oradores varones y seis oradoras mujeres, y estuvieron presentes argumentos a favor y en contra de esta medida. Es importante resaltar que muchos/as de los/as legisladores/as pusieron de relieve la operación en el mundo de una igualdad de tipo formal y otra igualdad de tipo material, y que muchas veces las leyes sólo operan en un plano de lo formal, pero que sin embargo, aunque no se transformen de manera inmediata las desigualdades materiales basadas en el género, sí opera, con la sanción de este tipo de leyes, una reparación simbólica que puede funcionar como puntapié de transformaciones materiales. Es interesante destacarlo, dado que los/as legisladores/as tenían noción de la transformación política que representa una ley de paridad de género, pero sabiendo que aún hay muchas desigualdades más que transformar, como lo expresa una diputada:

Estamos votando una ley de cupo mientras estamos hambreando a las compañeras en nuestros barrios. Estamos votando una ley de cupo mientras las compañeras tienen que ponerse al frente de merenderos y volver a abrir los comedores, porque los pibes no tienen para comer ${ }^{5}$. Así que si queremos discutir el acceso real de las mujeres a la política, empecemos por discutir la dignidad de las compañeras, que no van a poder, ni siquiera, llegar a jubilarse (Diputada Portos).

\footnotetext{
${ }^{5}$ Esta afirmación hace referencia a un contexto recesivo y de recortes sociales que se puso en marcha con la asunción del último gobierno nacional y provincial, de corte neoliberal.
} 
Revista Punto Género № 8. Diciembre de 2017

ISSN 0719-0417 / 39 - 54

Los argumentos a favor de la ley destacan que esta propuesta está acorde a la normativa internacional firmada por nuestro país y que lo obliga, como también en sintonía con otros países que ya tienen leyes de este tipo, como por ejemplo: Francia, España, Costa Rica, Bolivia, México, Nicaragua y Ecuador. Siempre el sistema internacional ha servido en nuestro país como fuente de legitimidad para las iniciativas nacionales.

Centrándonos en las resistencias contra la sanción de esta ley, podemos clasificar los argumentos en cuatro tipos: aquellos que se refieren a la igualdad de oportunidades entre mujeres y varones que esta ley vulneraría; aquellos argumentos que se refieren a una excesiva intromisión del Estado en la vida de los partidos políticos, los argumentos que abogan por la idoneidad de los/as candidatos/as y cómo esta ley iría contra este principio y, por último, aquellos argumentos relativos a una desigualdad material que esta ley no transformaría.

En relación con el primero de los argumentos en contra de la ley referidos, un diputado se basa en una supuesta igualdad de oportunidades para mujeres y varones que estaría, de hecho, garantizada mediante la igualdad formal. Para él, esta ley no es necesaria, porque ya tendríamos garantizada la igualdad de oportunidades con los varones, invisibilizando que "los varones siguen siendo los privilegiados en la confección de listas electorales y, consecuentemente, en el acceso a los cargos" (Diputada Sánchez). En estos términos, las mujeres no integraríamos en mayor número las listas porque no queremos o porque no nos esforzamos lo suficiente.

El segundo grupo de argumentos contrario a la ley se basa en la condenada intromisión del Estado en la vida interna de los partidos políticos. El tercer grupo de argumentos en contra nos resulta el más interesante: se basa en la capacidad o idoneidad de los/as candidatos/as, argumento que va en línea con la supuesta igualdad de oportunidades que ya estaría garantizada:

De esa manera, la calidad de la representación institucional disminuye, sea hombre o sea mujer, es lo mismo. Por eso la Ley de Cupo estableció un piso a partir del cual se dejaba jugar libremente a la persona humana, al que tiene más voluntad, más vocación, más capacidad, más trabajo, al que le pone más horas a esto o mejor representatividad, sea hombre o sea mujer. No se enojen, compañeras, sea hombre o sea mujer. (Diputado Giacobbe)

¿Es la representación una cuestión de idoneidad, o simplemente de representación? ¿Es que las mujeres no somos idóneas para ocupar ciertos lugares? ¿Siempre los varones están mejor preparados que nosotras y por ello es que integran las listas en mayoría? ¿No existen mecanismos informales, dentro de la propia militancia partidaria, que deja a las mujeres al margen de los lugares donde se toman decisiones? Creemos que sí, que el techo de cristal existe, que no se ve, pero ahí está. Este argumento de la idoneidad se ha ido reciclando a 
Revista Punto Género № 8. Diciembre de 2017

ISSN 0719-0417 / 39 - 54

través del tiempo, se vio en los debates de los años '30, en ocasión de discutir la ley de cupo en los años ' 90 y aún hoy sigue vigente, a pesar de que las mujeres solemos formarnos mucho más que los varones para ocupar los mismos lugares.

El último de los argumentos en contra, sostenido por partidos de izquierda, hace hincapié en que las igualdades formales que consagran este tipo de leyes no transformarían las desigualdades materiales, y que sólo sería un lavado de cara al sistema patriarcal sin conmover sus fundamentos, el mismo argumento que utilizó Marx en la cuestión judía cuando se refería a la participación política de los judíos.

La participación equitativa de las mujeres en los lugares de toma de decisiones es vital para reforzar, reafirmar y transformar la democracia participativa, el camino a la democracia genérica que propone Marcela Lagarde (2012). Sin embargo, esta participación tiene que ser conminada mediante leyes prescriptivas, dado que a pesar de tener una ley de cupo desde hace 26 años, las mujeres rara vez se encuentran en un porcentaje mayor a ese $30 \%$ que manda la ley. La pregunta que subyace es: ¿qué pasaría si esa ley no existiera? ¿En qué medida participarían las mujeres en las listas electorales? Las mujeres en el poder legislativo de la provincia de Buenos Aires ocupan el 33 por ciento de las bancas en la Cámara de Diputados y sólo el 26 por ciento en el Senado de la Provincia, tal como comenta la diputada Portos:

En agosto de 2011 tenía 25 años e integraba la lista de diputados provinciales de la Primera Sección Electoral por mi partido, el Frente para la Victoria, y en una reunión con otros actores políticos, un compañero me dijo: "no te hagas la canchera, que vos sos cupo". Ahí invalidó mi opinión. Y en ese momento, señor Presidente, yo tuve una revelación. Desde ese momento me hice cargo de que si estoy sentada en esta banca, es porque soy cupo. Soy cupo y lo fui no solamente en ese momento sino que fui cupo también en muchas fotos, en muchas discusiones, en muchas reuniones, y estoy orgullosa de esa Ley de Cupo que el Movimiento Nacional Feminista logró años atrás, y que hoy se reivindica con este 50 y 50. (Diputada Portos)

Esta es la primera vez en el debate, pero no la última, en que se reconoce al movimiento feminista como el verdadero motor de la transformación del estatus de las mujeres en el marco de una sociedad patriarcal, como también se reconoce la trayectoria de muchas mujeres lideresas de nuestra historia nacional que hicieron posible ese cambio.

A lo largo del debate, también se denuncian otros espacios donde es imprescindible que haya leyes de este tipo: la justicia, el poder ejecutivo, los gremios, en los partidos políticos, destacando la presencia de estereotipos de género y la división sexual del trabajo en base a ellos, que ubican a las mujeres en espacios subalternos, muchas veces carentes de poder, o que cristalizan los roles tradicionales. 
Revista Punto Género № 8. Diciembre de 2017

ISSN 0719-0417 / 39 - 54

Por último, nos interesa resaltar que este tipo de iniciativas son transformadoras de la forma tradicional de hacer política:

[El voto femenino conseguido en 1947] es un voto mucho más democrático que el voto que el varón se dio para sí mismo. Cuando el varón construyó su voto lo hizo discriminando, dejando fuera a sus pares porque, tal vez, no tenían recursos o no sabían leer ni escribir. También, por alguna cuestión cultural, en los varones hay una necesidad de dejar alguien afuera, para fortalecer su autoridad o su autoestima, vaya uno a saber. Así, primero quedaron afuera los que no sabían leer ni escribir o los que no tenían propiedades, hasta que vino el voto universal, que no era universal, porque las mujeres no votábamos [...] en definitiva, cuando las mujeres peleamos, lo hacemos de una manera más democrática y más transversal. (Diputada Nazábal)

\section{Resistencias reeditadas: un fallo polémico}

No podemos dejar de referirnos a un polémico fallo que recientemente invalidó una lista integrada en su totalidad por mujeres, argumentando que la misma violaba la ley de cupo. En la Ciudad de Rosario la lista de partido político "Ciudad Futura", una conformada enteramente por mujeres, fue impugnada en la Justicia Nacional Electoral por "no respetar el porcentaje mínimo de representación de cada sexo", ahora, la pregunta que nos hacemos es: la ley ¿̇manda un piso mínimo realmente o se interpreta como un máximo?

La Cámara Electoral Nacional, que confirmó la sentencia de primera instancia, esto es, manda a adecuar e incorporar varones a la misma, dio entre sus argumentos en el voto mayoritario, una interpretación sin utilizar la perspectiva de género para dicho análisis, alegando que se debe "resguardar idéntico derecho para los hombres" (voto Dr. Alberto Ricardo Dalla Via), colectivo que entendemos, no es aquel al cual fue destinado una ley de discriminación positiva para el acceso a cargos electivos, ya que nunca necesitaron que el Estado promocione y garantice tales derechos para ellos.

Llama la atención, entre los considerandos, la lectura que se realiza acerca de la interpretación de las normas, aludiendo a que debe "hacerse integrando las normas en la unidad sistemática, comparándolas, coordinándolas y armonizándolas, de forma tal que haya congruencia y relación entre ellas" con relación a la Constitución Nacional, y el principio de igualdad real de oportunidades entre varones y mujeres en el acceso a cargos electivos (art. 37), pero haciendo caso omiso al objetivo de la sanción de la ley de análisis, los tratados internacionales sobre discriminación hacia la mujer, las recomendaciones para disminuir la brecha y la realidad que envuelve al colectivo de mujeres políticas.

Cabe destacar el voto en disidencia del Dr. Corcuera, quien en el recorrido de sus argumentos interpretó el principio de "igualdad real", apelada por sus compañeros en el voto mayoritario, diciendo que "ha resultado ser omiso y ciego ante las desigualdades de 
Revista Punto Género № 8. Diciembre de 2017

ISSN 0719-0417 / 39 - 54

género, al no reconocer las múltiples dimensiones de desventajas, subordinación y discriminación sistemáticas y estructurales hacia las mujeres, que impiden su participación de manera equilibrada con los hombres en el ámbito de la política" (conf. Cons. № 4), dando a entender el desigual punto de partida entre ambos géneros.

A su vez, hace hincapié en que la ley y su correspondiente decreto reglamentario son muy claros al apuntar su objetivo a "la necesidad de equiparar la desigualdad que históricamente han sobrellevado las mujeres en cuanto a la diferencia de oportunidades políticas" (id) y por lo tanto no puede ser aplicado a los varones, ya que atenta contra el sentido de dicha ley, su espíritu y resulta una paradoja.

Finalmente la lista fue presentada incorporando varones, pero en calidad de "candidatos en rebeldía", los cuales acompañarían, pero su meta no es obtener un cargo electivo, cumpliendo así el mandato de la Cámara. Esta vez fue el discurso judicial el que legitima la desigualdad de género en la representación político partidaria, con argumentaciones erróneas acerca de cómo se interpreta la ley de cupo: ¿a quiénes se pretende garantizar la cuota con esta ley? Claramente al grupo desaventajado socialmente, es decir, a las mujeres, a aquellas que sin la ley, no integraríamos las listas electorales.

\section{Reflexiones finales}

La ampliación de derecho siempre es resultado de la demanda, de la lucha de los colectivos, es el resultado de la confluencia de voluntades políticas y sociales. Los derechos políticos de las mujeres no son una excepción. Como hemos observado a lo largo de este artículo, a lo largo de la historia argentina se puede apreciar los avances en el acceso relativo al ejercicio de los derechos civiles y políticos de las mujeres. La ley cumplió y cumple un rol destacado ante la resistencia de la sociedad, y sobre todo de aquellos que detentan privilegios y poder. Aunque el lobby del establishment hace lenta la evolución cultural en pos de una democracia genérica (Lagarde, 2012), las leyes que resuelven la correlación de fuerzas hacen que las medidas adoptadas en un momento histórico determinado, funcionen como un nuevo piso -y no como techo- para la lucha igualitaria.

La democracia genérica significa desarticular la alianza del Estado y el Patriarcado, reconocer los derechos de las mujeres como derechos humanos, lograr una equidad de género, pero sobre todo "eliminar las formas estatales de tutelaje y control sobre las mujeres y eliminar la condición de minoría política de las mujeres en el Estado" (Lagarde, 2012:123). Y para lograr la democracia genérica, las leyes tienen potencial transformador. Como señala Alda Facio:

Aquí es importante que reflexionemos sobre lo mucho que se ha escrito acerca de la imposibilidad de cambiar actitudes y conductas por medio de la promulgación de una ley, especialmente en relación al «machismo». Recordemos cuántas veces el movimiento 
Revista Punto Género № 8. Diciembre de 2017

ISSN 0719-0417 / 39 - 54

feminista se ha tropezado con el argumento de que el "machismo» es una actitud "cultural» que sólo se puede ir cambiando lentamente a través de la educación y no por medio de leyes, argumento que es doblemente erróneo. Primero, no es cierto que el sexismo sea solamente una «actitud» cultural, porque como he venido diciendo es también un sistema con estructuras de poder bien concretas y establecidas. Y segundo, es erróneo porque está históricamente comprobado que la ley sí puede, y de hecho lo ha logrado, cambiar costumbres, mores, folkways o valores. Los conquistadores de todos los tiempos han modificado y hasta totalmente transformado costumbres y valores de los pueblos conquistados por medio de la promulgación de leyes, especialmente porque tienen el respaldo del aparato represivo del Estado para sancionar las conductas no deseadas por los conquistadores (Facio, 2009:196).

Compartimos entonces que las leyes no transforman la realidad material inmediatamente, pero sí inician una transformación simbólica que más tarde se materializa. En este sentido, las medidas como las cuotas tienen como característica principal y deseada su temporalidad,

[Las cuotas son medidas temporales que] se mantienen hasta lograr el objetivo principal, que no es otro que la consecución de la igualdad política entre hombres y mujeres. La paridad, por el contrario, es una medida definitiva, que reformula la concepción del poder político, redefiniéndolo como un espacio que debe ser compartido igualitariamente entre hombres y mujeres. (Albaine 2014)

Aunque algunas de las críticas a este tipo de medidas se centran en que el aumento de mujeres en recintos legislativos no garantiza que todas las que accedan a los lugares de toma de decisiones sean feministas y tengan una perspectiva de género que apliquen en los debates, la importancia radica en la representación, en la dimensión simbólica de poder naturalizar que las mujeres podemos ocupar puestos de poder, como también en el abanico de temas que se abre, en los temas que interesan particularmente al colectivo, y que generalmente son presentados por mujeres, en definitiva: en la capacidad de las mujeres de poner en la agenda pública-política los temas de género. Y esos fueron los argumentos más fuertes a favor de la paridad.

En cuanto a los argumentos en contra, podemos clasificarlos en dos tipos: aquellos de tipo institucionales (no meterse en la vida interna de los partidos) y aquellos relativos a la capacidad para ocupar cargos: la cuestión de la igualdad de oportunidades aparentemente ya existente y garantizada mediante la ley de cupo (lo cual es una contradicción en sus propios términos), y aquel argumento relativo a la idoneidad. Sin profundizar en cuán preparadas estamos las mujeres que llegamos a determinados lugares, y sin problematizar la idoneidad de los varones que ocupan puestos de poder, este argumento remite a cierta concepción roussoniana de idoneidad: aquella plasmada en El Emilio, que plantea una idoneidad natural de los varones para los asuntos públicos, y una idoneidad natural de las 
Revista Punto Género № 8. Diciembre de 2017

ISSN 0719-0417 / 39 - 54

mujeres para la domesticidad. Aquella idoneidad que dejó a las mujeres sin derechos políticos en la Francia de 1789, y esta idoneidad que se reedita para restringir los derechos políticos de las mujeres en la actualidad.

Queremos cerrar este artículo con algunas inquietudes: ¿Por qué son necesarias este tipo de leyes? Si no existieran leyes de este tipo, ¿las mujeres seriamos elegidas? ¿Resulta una paradoja recurrir al estado patriarcal para asegurar los derechos de las mujeres? En este estado de cosas pensamos que las mujeres tenemos más que paradojas para ofrecer.

\section{BIBLIOGRAFÍA}

Albaine, Laura (2014): "Obstáculos y desafíos de la paridad de género. Violencia política, sistema electoral e interculturalidad," en Íconos Revista de Ciencias Sociales. Disponible en http://revistas.flacsoandes.edu.ec/iconos/article/viewFile/1675/1304

Ansaldi, Waldo, (1999): “Crear el sufragante: la universalización masculina de la ciudadanía política en argentina. La reforma electoral de 1912" en Anales, Nueva Época, 2, Suecia. $\quad[O n$ line] Disponible en http://www.catedras.fsoc.uba.ar/udishal/art/crearsufragante.pdf

Barrancos, Dora (2007): Mujeres en la sociedad argentina. Una historia de cinco siglos. Buenos Aires: Sudamericana.

Facio, Alda (2009): “Metodología para el análisis de género del fenómeno legal”, en Ávila Santamaría, Ramiro; Salgado, Judith; Valladares, Lola (Comps.): El género en el derecho. Ensayos críticos. Ecuador: Ministerio de Justicia y Derechos Humanos.

Krook, Mona Lena y Juliana Restrepo Sanín (2016): Género y violencia política en América Latina Conceptos, debates y soluciones. [On line] Disponible en http://iknowpolitics.org/sites/default/files/genero-y-violencia-politica.pdf (recuperado el 02/03/2017).

Lagarde y de los Ríos, Marcela (2012): El feminismo en mi vida. Hitos, claves y topías. Ciudad de México: Instituto de las Mujeres del Distrito Federal.

Llanos, Beatriz y Roza Viviana (2015): Partidos políticos y paridad: Un desafío de la democracia en América Latina. [On line] Disponible en https://publications.iadb.org/bitstream/handle/11319/7356/int320.PDF?sequence= $\underline{1}$

Olsen, Frances (2009): "El sexo del derecho". En Ávila Santamaría, R., Salgado, J. y Valladares, L. (Comps.): El género en el derecho. Ensayos críticos. Ecuador: Ministerio de Justicia y Derechos Humanos. 
Revista Punto Género № 8. Diciembre de 2017

ISSN 0719-0417 / 39 - 54

Palermo, Silvana (2007): Quiera el hombre votar, quiera la mujer votar. Género y ciudadanía política en Argentina (1912-1947). [On line] Disponible en http://historiapolitica.com/datos/biblioteca/palermo.pdf

Pateman, Carole (1995): El Contrato Sexual. México: Anthopos/UAM.

Perrot, Michelle (2008): Mi historia de las mujeres. Argentina: Fondo de Cultura Económica.

Valobra, Adriana (2008): “Feminismo, sufragismo y mujeres en los partidos políticos en la Argentina de la primera mitad del siglo XX" en @mnis, Revue de civilisation contemporaine de l'université de Bretagne Occidentale (UBO, Brest). [On line] Disponible en http://amnis.revues.org/666

Valobra, Adriana (2010): Del hogar a las urnas. Recorridos de la ciudadanía política femenina. Argentina, 1946-1955, Rosario: Prohistoria, Disponible en http://es.scribd.com/doc/34053743/DEL-HOGAR-A-LAS-URNAS 